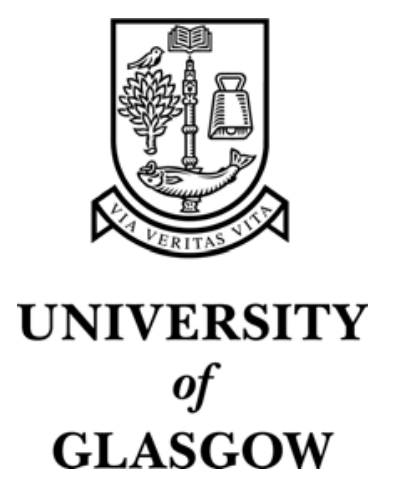

Bain, D.T. (2004) Private languages and private theorists. Philosophical Quarterly 54(216):pp. 427-434.

http://eprints.gla.ac.uk/3375/ 


\title{
Private Languages and Private Theorists
}

[Published in Philosophical Quarterly, vol. 54, no. 216, July 2004, pp. 427-34.

ISSN 0031-8094. The definitive version is available at www.blackwell-synergy.com]

\begin{abstract}
Simon Blackburn objects that Wittgenstein's private language argument overlooks the possibility of a private linguist equipping himself with a criterion of correctness by confirming generalisations about the patterns in which his private sensations occur. Crispin Wright responds that appropriate generalisations would be too few to be interesting. But I show that Wright's calculations are upset by his failure to appreciate both the richness of the data and the range of theories that would be available to the linguist.
\end{abstract}

Wittgenstein famously poses a problem for the idea of a private language, i.e. a language no two people could have reason to believe they share, as a language for describing sensations would be, if sensations were in principle inaccessible to anyone but their subjects. The problem the aspirant speaker of such a language faces, according to Wittgenstein, is that he could never reasonably convict himself of incorrect uses of its terms. He would, Wittgenstein says, "have no criterion of correctness", and hence he would not really be speaking a language at all (1953, \$258).

Simon Blackburn and Crispin Wright agree this is Wittgenstein's point.' But Blackburn thinks Wittgenstein overlooks that a speaker might regulate his use of a private sensation language by exploiting well confirmed generalisations about the patterns in which his sensations occur. $^{2}$ Wright offers Wittgenstein an intriguing response: even if an aspirant speaker might do this, not just any generalisation will do; indeed, it turns out that the ratio of useful to useless generalisations is so small that there is only a negligible probability of one's being able to equip oneself to understand a language in the proposed way.

In what follows, I argue that Wright's assessment of the aspirant linguist's chances is flawed. Though I suspect Wittgenstein can successfully be defended against Blackburn, my business in this paper is simply to show why, in doing so, one must not concede as much to Blackburn as Wright does.

\section{BLACKBURN'S PROPOSAL}

Let $\mathrm{P}_{1}$ be a phenomenological category of sensations. Suppose a subject, $A$, undergoes sensations at times $\mathrm{t}_{1}$ and $\mathrm{t}_{2}$. $A$ judges at $\mathrm{t}_{1}$

$\mathrm{s}_{1}$ : I am undergoing a $\mathrm{P}_{1}$ sensation,

and is inclined to judge at $t_{2}$ both not-s 1 and

\footnotetext{
${ }^{1}$ See Blackburn (1984) and Wright (1986), to which all page references refer.

${ }^{2}$ See also Harrison (1974, p. 161), Walker (1978, p. 115), and Carruthers (1986, ch. 6).
} 
$\mathrm{H}$ : the sensation I am undergoing is of the same phenomenological type as the sensation I was undergoing at $t_{1}$.

$A$ 's inclinations at $\mathrm{t}_{2}$ are insufficient to justify a verdict that his earlier judgement, $\mathrm{s}_{1}$, was false. He might just as well deny either $\mathrm{H}$ or not-s 1 . So the example does not show that $A$ has a criterion of correctness. But, Blackburn argues, $A$ would have more to go on than mere classificatory inclinations if he became a theorist about his sensations, engaged in a "project ... of ordering the expectation of the occurrence of sensation, with an aim at prediction, explanation, systematisation" (pp. 299-300). Instead of H being a mere impression of the phenomenological identity of two sensations, for example, $A$ might have established a correlation between two or more sensation types. Theories are ultimately answerable to observation, of course, but such a correlation might be sufficiently well confirmed to warrant, in a given case, protecting it against a putative counterexample by rejecting a particular sensation judgement instead. Of course, $A$ would still have to choose which particular sensation judgement to revoke. (After all, in the example above, even if there were reason to protect $\mathrm{H}$, there would still be a choice as to which of $\mathrm{s}_{1}\left(\mathrm{t}_{1}\right)$ and not- $\mathrm{s}_{1}\left(\mathrm{t}_{2}\right)$ to revoke.) But if $A$ confirms more correlations and has more classificatory inclinations, the idea is that he could make a principled decision on this further matter too. So equipped, Blackburn thinks, $A$ could exploit such theoretical ideals as simplicity to underpin his verdicts about the correctness and incorrectness of his sensation judgements.

Wright illustrates Blackburn's proposal as follows (pp. 239-41). ${ }^{3}$ Suppose $A$ undergoes three types of sensation: $\mathrm{P}_{1}, \mathrm{P}_{2}$, and $\mathrm{P}_{3}$. Let " $\mathrm{S}_{1}$ " abbreviate "I underwent a $\mathrm{P}_{1}$ sensation at some point in the preceding six minutes", "not- $S_{1}$ " abbreviate "I did not undergo a $\mathrm{P}_{1}$ sensation during the preceding six minutes"; and read " $\mathrm{S}_{2}$ ", "not- $\mathrm{S}_{2}$ ", "S $\mathrm{S}_{3}$ ", and "not- $\mathrm{S}_{3}$ " similarly, mutatis mutandis. (Note that I intend the capital "S" to distinguish these past-tense judgements from the present tense $\mathrm{s}_{1}$, above.) Suppose that, during an extended period, $A$ confirms that the following pattern is exhibited over any six minutes: "If I did not undergo a $\mathrm{P}_{1}$ sensation in the preceding six minutes, then I underwent a $\mathrm{P}_{2}$ sensation; if I underwent a $\mathrm{P}_{3}$ sensation, then I did not undergo a $\mathrm{P}_{2}$ sensation". This can be represented using the material conditionals

$$
\begin{aligned}
& \mathrm{H}_{1}: \sim \mathrm{S}_{1} \rightarrow \mathrm{S}_{2} \\
& \mathrm{H}_{2}: \mathrm{S}_{3} \rightarrow \sim \mathrm{S}_{2} .
\end{aligned}
$$

Now, there are eight internally consistent sets of judgement $A$ might make about any six minutes. Wright represents these "diary types", as I call them, as follows:4

\footnotetext{
${ }^{3}$ I have changed some minor aspects of Wright's presentation.

${ }^{4}$ The right-hand side of the table is my elaboration, explained below.
} 


\begin{tabular}{cccc|l} 
Diary type & $\mathbf{S}_{1}$ & $\mathbf{S}_{2}$ & $\mathbf{S}_{3}$ & Is the diary consistent with $\left\{\mathbf{H}_{1}, \mathbf{H}_{2}\right\} ?$ \\
\hline $\mathbf{1}$ & T & T & T & X \\
$\mathbf{2}$ & T & T & F & $\checkmark$ \\
$\mathbf{3}$ & T & F & T & $\checkmark$ \\
4 & T & F & F & $\checkmark$ \\
$\mathbf{5}$ & F & T & T & X oC for $\mathrm{S}_{3}$ \\
$\mathbf{6}$ & F & T & F & $\checkmark$ \\
7 & F & F & T & X OC for not- $\mathrm{S}_{1}$ \\
$\mathbf{8}$ & F & F & F & X
\end{tabular}

Here, an "F" under $S_{1}$ on the fifth row means that one of the three judgements in a type- 5 diary is not- $S_{1}$.

We can now apply Blackburn's idea to the judgement type, $\mathrm{S}_{3}$. Suppose $A$ records a type-5 diary, judging not- $\mathrm{S}_{1}, \mathrm{~S}_{2}$, and $\mathrm{S}_{3}$. The conjunction of $\mathrm{S}_{2}$ and $\mathrm{S}_{3}$ is inconsistent with $\mathrm{H}_{2}$, so a correction is needed. Since $\mathrm{H}_{2}$ is, unlike $\mathrm{H}$ in the original example, a well confirmed correlation, $A$ can reasonably try to preserve it, narrowing the candidates for revision to two: $\mathrm{S}_{2}$ and $\mathrm{S}_{3}$. Of these, $\mathrm{S}_{2}$ is corroborated by $A$ 's judgement, not- $\mathrm{S}_{1}$ : given $\mathrm{H}_{1}$, revoking $\mathrm{S}_{2}$ (i.e. substituting not- $\mathrm{S}_{2}$ ) would require also revoking not- $\mathrm{S}_{1}$. So it is simpler for $A$ to revise $\mathrm{S}_{3}$ instead. Hence Blackburn seems vindicated. $A$ appears to have what Wittgenstein denied he could have: a criterion of correctness for $\mathrm{S}_{3}$. Again, given $\left\{\mathrm{H}_{1}, \mathrm{H}_{2}\right\}, A$ 's recording a type-5 diary appears to be a circumstance in which he can reasonably revise a judgement of $S_{3}$, thereby deciding that the correct account of his inner life over those six minutes was a diary not of type-5, but of type- 6 .

\section{WRIGHT'S OBJECTION}

Relative to a theory, a diary type is what I call "optimally correctable" (OC) for a type of sensation judgement, $\mathrm{S}_{\mathrm{i}}$, if and only if any diary of that type is such that

(i) it includes a judgement of $S_{i}$

(ii) it is inconsistent with the theory,

(iii) consistency can be restored in a way that involves revising $S_{i}$ within that diary, and

(iv) all other ways of restoring consistency involve more corrections to that diary than ways that involve revising, within that diary, $\mathrm{S}_{\mathrm{i}}{ }^{5}$

Hence the preceding paragraph shows that $\left\{\mathrm{H}_{1}, \mathrm{H}_{2}\right\}$ renders the fifth diary type OC for $\mathrm{S}_{3}$, as it does the seventh type for not- $S_{1}$. But, to appreciate Wright's claim that not just any

\footnotetext{
${ }^{5}$ The terminology and formulation are mine, but see Wright (1986), p. 241, pp. 246-8, and p. 259.
} 
generalisation will serve the private linguist's purposes, begin by noticing that $\left\{\mathrm{H}_{1}, \mathrm{H}_{2}\right\}$ fails, by contrast, to generate OC diary types for $S_{1}, S_{2}$, not- $S_{2}$, and not- $S_{3,}$. For these judgements, any diary type satisfying the first three conditions for being OC fails the fourth.

In the case of $S_{1}$ and not- $S_{3}$, for example, they fail because, if any diary inconsistent with $\left\{\mathrm{H}_{1}, \mathrm{H}_{2}\right\}$ were recorded, there would be a way of restoring consistency that involved fewer corrections to that diary than ways that involve revising the judgement, within that diary, either of $S_{1}$ or of not- $S_{3}$. Take $S_{1}$, for example. Type-1 diaries are the only type inconsistent with $\left\{H_{1}\right.$, $\left.\mathrm{H}_{2}\right\}$ that involve $\mathrm{S}_{1}$. And, admittedly, if one were recorded, consistency could be restored by revising $S_{1}$ and $S_{3}$ together. But it could also be restored by revising either $S_{2}$ or $S_{3}$ alone. So $S_{1}$ lacks an $\mathrm{OC}$ diary relative to $\left\{\mathrm{H}_{1}, \mathrm{H}_{2}\right\}$.

In the case of $S_{2}$ and not- $S_{2}$, relevant diaries fail the fourth condition because, if any diary inconsistent with $\left\{\mathrm{H}_{1}, \mathrm{H}_{2}\right\}$ were recorded, there would be a way of restoring consistency that involved the same number of corrections to that diary as ways that involve revising the judgement, within that diary, either of $S_{2}$ or of not- $S_{2}$. Take $S_{2}$, for example. The only diaries that are both recalcitrant and contain $S_{2}$ are type-1 and type-5. If a type-1 diary were recorded, admittedly, consistency could be restored by revising $S_{2}$, but it could also be restored by revising $S_{3}$. As for type- 5 diaries, we have already seen that, if one were recorded, the way of restoring consistency that would involve fewest corrections to that diary would be revising its judgement of $S_{3}$, not $S_{2}$. So $\mathrm{S}_{2}$ lacks an $\mathrm{OC}$ diary relative to $\left\{\mathrm{H}_{1}, \mathrm{H}_{2}\right\}$.

Now, Wright's objection to Blackburn crucially, if implicitly, involves the following conditional:

W: a generalisation determines a criterion of correctness for a putative judgement type, $\mathrm{S}_{\mathrm{i}}$, only if it determines an OC diary type for $\mathrm{S}_{\mathrm{i}}$.

W can be seen to be operative, for example, in Wright's slide from the preceding account of why $\mathrm{S}_{2}$ lacks an OC diary type to the view that there is no situation in which it would be reasonable for $A$ to revoke a judgement of $\mathrm{S}_{2}$ (pp. 241-2). Assuming that the simplest way to restore consistency is the most reasonable, and noticing that the only recalcitrant diaries involving $\mathrm{S}_{2}$ are the first and fifth, Wright clearly has the following idea. On the one hand, if a type-1 diary were recorded, then no correction would be reasonable, since, although revoking $S_{2}$ and revoking $S_{3}$ would both be more simple corrections than any others, neither would be more simple than the other, and hence there would be no basis for choosing which to make. On the other hand, if a type-5 diary were recorded, the simplest and hence most reasonable way of restoring consistency would involve revoking $\mathrm{S}_{3}$, not $\mathrm{S}_{2}$. Thus using W, Wright concludes that, relative to $\left\{\mathrm{H}_{1}, \mathrm{H}_{2}\right\}, A$ lacks a criterion of correctness for $S_{2}$. And he draws the same conclusion for $S_{1}$, not- $S_{2}$, and not$S_{3}$. Hence these fail to be types of genuine judgement. 
In three steps, Wright reaches a more ambitious conclusion. First, he suggests that a judgement can be genuine only if its truth-functional compounds are, and that merely putative judgements could hardly render a diary inconsistent with a theory. Hence he argues that the lack of criteria of correctness for $S_{1}, S_{2}$, not- $S_{2}$, and not- $S_{3}$ has a "rotten apple effect", undermining the prima facie claim of the remaining types to being genuine (pp. 242-3). Second, Wright thinks this rotten apple effect makes plausible a further conditional: a theory will generate criteria of correctness for judgements about any sensation types it concerns only if it generates criteria of correctness for judgements about all of those types (p. 247). Given W, this means that a theory must generate $O C$ diaries for all such judgements. Third, Wright presents extensive formal work (due largely to Warren Goldfarb), aiming to show that the ratio of theories that meet this condition to theories that fail it is very small, and smaller the more types of sensation the theories concern (pp. 258-266). Thus, he concludes, $A$ has a very low chance of confirming a theory equipping him to speak a private language. If, for instance, the theory in question is to range over four sensation types, then on Wright's calculations there is a one in 8,192 chance of an aspirant private linguist confirming a correlation that fits the bill!

Wright thinks this conclusion will worry friends of privacy for two reasons (p. 250): first, because he has shown that Blackburn's theorising proposal makes the possibility of a subject's speaking a private language contingent on the precise patterns in which his sensations occur; and second, because Wright thinks he has shown that the chances of a subject's sensations exhibiting an appropriate pattern is very small. Even if these two points are right, however, it is unclear why friends of privacy need be anxious. For one thing, it is surely Wittgenstein, rather than friends of privacy, who would reject the dependence of private sensation languages on the patterns the sensations exhibit. As Wright concedes, Wittgenstein seems to think a private language is logically impossible; he would surely not be insouciant about its being merely improbable. For another thing, friends of privacy might be. They might point out the following parallel: that Wittgenstein's own rule-following considerations show the possibility of a public language to be highly contingent. ${ }^{6}$ That contingency is tolerable, they might say, if only because the actual world is patently one in which public language is possible; and they might suggest that Wright's probabilities in the private case are tolerable too, on parallel grounds. Be all that as it may, the objection I want to develop against Wright is different: namely, even if the private language issue were one of the aspirant linguist's odds, Wright has underestimated them.

\section{CONDITIONAL $\mathrm{W}$}

One important reason Wright underestimates the private linguist's chances is that W, the crux of Wright's calculations, is false. To take one of its counterexamples, $\left\{\mathrm{H}_{1}, \mathrm{H}_{2}\right\}$ does

\footnotetext{
${ }^{6}$ See Moore (2003).
} 
determine circumstances in which $A$ would have grounds for correcting a judgement of $\mathrm{S}_{2}$, notwithstanding the fact that $\left\{\mathrm{H}_{1}, \mathrm{H}_{2}\right\}$ does not provide an $\mathrm{OC}$ diary for $\mathrm{S}_{2}$. (Or, to exercise proper caution, $\left\{\mathrm{H}_{1}, \mathrm{H}_{2}\right\}$ determines criteria of correctness for that judgement type unless such criteria are undermined by the rotten apple effect, to which I return below.)

To see this, recall that $\left\{\mathrm{H}_{1}, \mathrm{H}_{2}\right\}$ is a theory confirmed as holding over any six minutes. Now Wright is thinking of $A$ 's diaries being recorded in serial succession, concerning consecutive periods of six minutes. This undermines the natural reply against Wright that, if $A$ records a recalcitrant diary that cannot be non-arbitrarily revised now, then $A$ might for the time being continue to record his classificatory inclinations until he provides himself with sufficient data to enable a later principled revision of that earlier diary. This reply is undermined because, when we think of diaries recorded in serial succession, it is difficult to see how a collection of diaries which individually provide no reason to change $\mathrm{S}_{2}$ could fare any better collectively. However, if $\left\{\mathrm{H}_{1}, \mathrm{H}_{2}\right\}$ holds over any six minute period, there is no reason why we should follow Wright in thinking of it being applied only to diaries recorded in serial succession. Surely, $A$ can start a new diary as soon after its predecessor commences as he likes.

To flesh out this possibility, suppose that the past-tense judgements constituting a diary, such as "I underwent a $\mathrm{P}_{1}$ sensation at some point in the preceding six minutes" (that is, judgement $\mathrm{S}_{1}$ ), are based on present-tense judgements made during the six minutes in question, such as "I am undergoing a $\mathrm{P}_{1}$ sensation" (which judgement I abbreviate with the lower-case "s"). Suppose, then, that every two minutes, starting at $\mathrm{t}_{1}, A$ undergoes a sensation, about which he makes a present-tense judgement; and, every two minutes, starting at $t_{0}$, he begins a new sixminute diary. The crucial upshot is that, after six minutes, every token, present-tense judgement $A$ makes will contribute not to one diary, but to three, as illustrated below: 


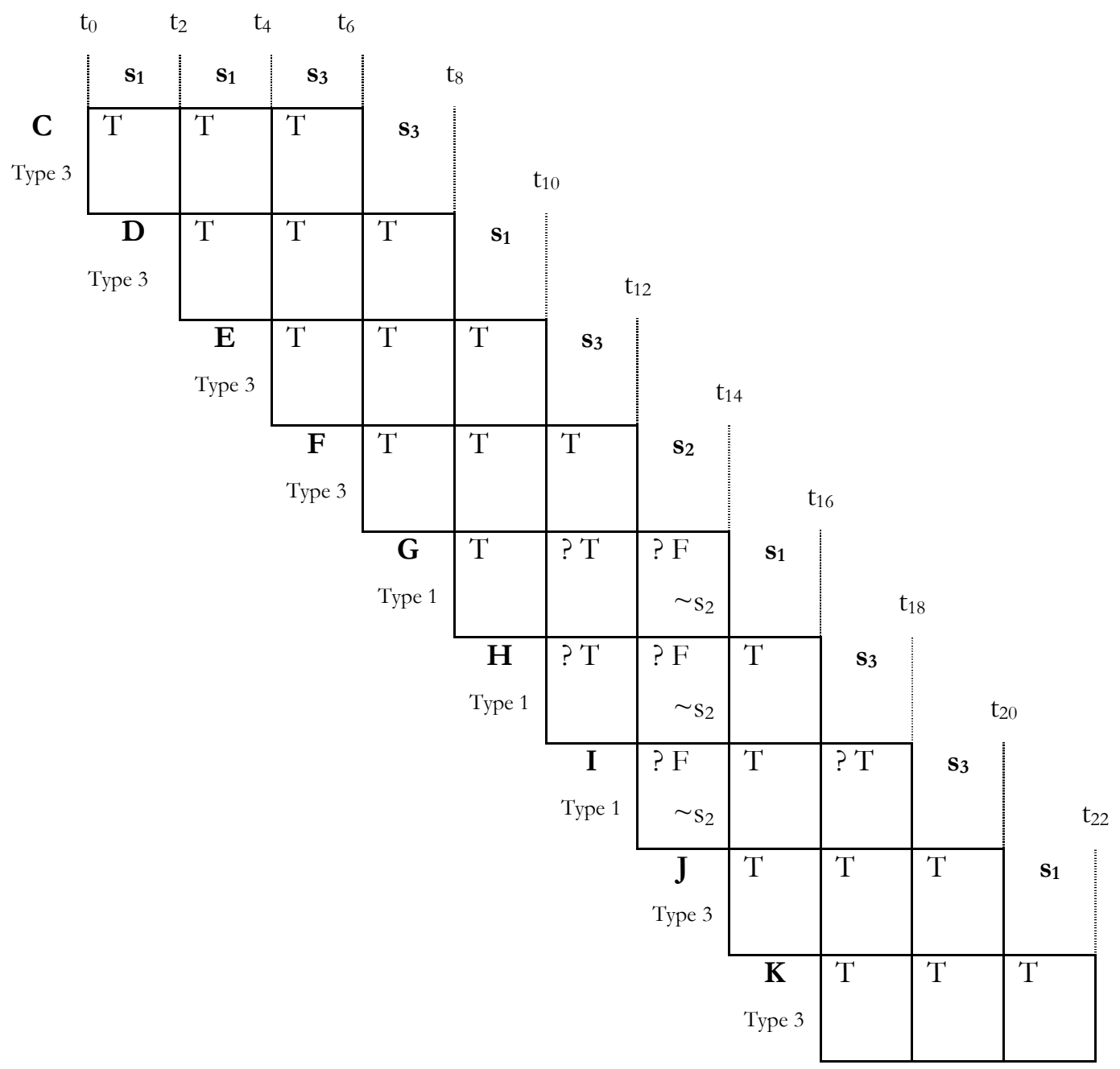

In this diagram, each horizontal row of three squares represents a diary, named with a letter to its left.? The abbreviation above each square represents the present-tense judgement the private linguist makes when he undergoes each sensation. Moreover, suppose that when $A$ judges that a sensation of one type occurs, he simultaneously judges that sensations of the other types do not. When he judges $\mathrm{s}_{1}$, for example, he also judges not-s $\mathrm{s}_{2}$ and not- $\mathrm{s}_{3}$. Hence by $\mathrm{t}_{6}$, for example, $A$ has recorded a type- 3 diary, $\mathrm{C}$, since the record of his present-tense judgements between $\mathrm{t}_{0}$ and $\mathrm{t}_{6}$ determines the pre-theoretical, past-tense conclusion that, while sensations of types $\mathrm{P}_{1}$ and $\mathrm{P}_{3}$ have occurred over that period, no sensation of type $\mathrm{P}_{2}$ has. Now, a "T" in a box indicates a post-theoretical confirmation of a pre-theoretical judgement; an " $\mathrm{F}$ " indicates a post-theoretical revision, the new judgement being written beneath the "F"; a question mark indicates that a judgement is one of a pair in that diary such that, though one should be revised, there is no basis at the time of completing the diary for a principled decision as to which.

\footnotetext{
${ }^{7}$ Strictly, a diary is a set of three past-tense, not present-tense, judgements. But my relaxation in usage is unproblematic, provided past-tense judgements made at the end of the six minute period reflect present-tense judgements made during it.
} 
The significance of the diaries' overlapping is this: if $A$ revokes the $\mathrm{t}_{13}$ judgement of $\mathrm{s}_{2}$ in diary I, for example, $A$ thereby revokes it in diaries $\mathrm{G}$ and $\mathrm{H}$, since the judgement $\mathrm{s}_{2}$ in all three diaries is one and the same token judgement. Crucially, then, overlapping diaries create the possibility that some alterations to a recalcitrant diary will solve up to three diaries (including itself) and some alterations to one diary will cause up to three diaries (including itself) to become recalcitrant. This provides more leverage for making principled revisions.

To see the counterexample to W, consider the diagram's details. After a series of four overlapping type- 3 diaries ( $C$ through $\mathrm{F}$ ), $A$ judges $\mathrm{s}_{2}$ at $\mathrm{t}_{13}$. This is the last entry in diary $\mathrm{G}$ (completed at $\mathrm{t}_{14}$ ), which is a recalcitrant type-1 diary, needing revision. At $\mathrm{t}_{14}$ (that is, looking only at diaries $C$ through $G$ ), there is no principled way of deciding which of $s_{2}$ and $s_{3}$ to revoke within $\mathrm{G}$. The subsequent completion of diary $\mathrm{H}$ is of no help either, since these two candidate corrections to $\mathrm{G}$, between which $A$ could not choose at $\mathrm{t}_{14}$, are identical to the two candidates corrections to $\mathrm{H}$ (also type-1) between which there is still no choosing. The ratio of solved diaries to revised judgements would be $2: 1$ for each of $\mathrm{s}_{2}$ and $\mathrm{s}_{3}$. However, the completion at $\mathrm{t}_{18}$ of diary I (type-1 again) is helpful, since it is now the case that changing one token judgement of $\mathrm{s}_{2}$ $\left(t_{13}\right)$ would solve three diaries $(G, H$, and $I)$ whereas a revision to $s_{3}$ could achieve such a reward only at the greater cost of changing two token judgements $\left(t_{11}\right.$ and $\left.t_{17}\right)$. Moreover, a provisional correction of $\mathrm{s}_{2}$ would not be upset by the completion of diaries $\mathrm{J}$ and $\mathrm{K}$, since these are not recalcitrant and thus cannot be solved (since they do not need solving) by a change to the $\mathrm{t}_{17}$ judgement of $\mathrm{s}_{3}$.

On its face, this is a situation in which, guided by the ideal of simplicity, $A$ has precisely what Wright thinks he could never have: a reason to revise his judgement $S_{2}$ (and the presenttense $\mathrm{s}_{2}$ ), generated by the correlation $\left\{\mathrm{H}_{1}, \mathrm{H}_{2}\right\}$, despite the fact that $\mathrm{S}_{2}$ lacks an OC diary. A similar example can be given for not- $S_{2}$. Therefore Wright's conditional, $\mathrm{W}$, which makes an OC diary a necessary condition for a criterion of correctness, is false.

\section{NEGLECTED THEORIES}

My conclusion might seem premature, given Wright's claim that a theory will generate criteria of correctness for judgements about any of the sensation types it concerns only if it generates them for judgements about all those types. Overlapping diaries meant that we could generate prima facie criteria of correctness for more judgement types than could Wright, but since I doubt that we can use overlapping diaries to generate even prima facie criteria for $\mathrm{s}_{1}$ and not- $\mathrm{s}_{3}$, the rotten apple threat remains. Here, then, it is important to notice that Wright not only overlooks the use of overlapping diaries to enrich the putative linguist's data; he overlooks the range of theories that might be available to the linguist. Why, for example, might the linguist not consider theories concerning the temporal order of $A$ 's sensations? 
Suppose, for instance, that instead of $\left\{\mathrm{H}_{1}, \mathrm{H}_{2}\right\}$ (a theory comprising material conditionals), $A$ confirmed the following:

$$
\begin{array}{ll}
\mathrm{H}_{3}: & \mathrm{P}_{1} \Rightarrow \mathrm{P}_{2} \\
\mathrm{H}_{4}: & \mathrm{P}_{2} \Rightarrow \mathrm{P}_{3} \\
\mathrm{H}_{5}: & \mathrm{P}_{3} \Rightarrow \mathrm{P}_{1} .
\end{array}
$$

Read $\mathrm{H}_{3}$ as "a sensation of type $\mathrm{P}_{1}$ will be succeeded by a sensation of type $\mathrm{P}_{2}$ before a sensation

\begin{tabular}{|c|c|c|c|c|c|c|c|c|c|c|}
\hline $\mathrm{t}_{1}$ & $\mathrm{t}_{2}$ & $t_{3}$ & $\mathrm{t}_{4}$ & $\mathrm{t}_{5}$ & $\mathrm{t}_{6}$ & $\mathrm{t}_{7}$ & $\mathrm{t}_{8}$ & $\mathrm{t}_{9}$ & $\mathrm{t}_{10}$ & $\mathrm{t}_{11}$ \\
\hline $\mathrm{S}_{1}$ & $\mathrm{~S}_{2}$ & $\mathrm{~S}_{3}$ & $\mathrm{~S}_{1}$ & $\mathrm{~S}_{2}$ & $\mathrm{~S}_{3}$ & $\mathrm{~S}_{1}$ & $\mathrm{~s}_{1}$ & $\mathrm{~S}_{3}$ & $\mathrm{~S}_{1}$ & $\mathrm{~S}_{2}$ \\
\hline
\end{tabular}
of another type", and read $\mathrm{H}_{4}$ and $\mathrm{H}_{5}$ similarly, mutatis mutandis. Now imagine that $A$ records the following series of pre-theoretical judgements:

As before, suppose that every time $A$ judges that he is undergoing a sensation of one type, he simultaneously judges that he is not undergoing either of the other types. Now, having recorded this set of pre-theoretical judgements between $\mathrm{t}_{1}$ and $\mathrm{t}_{12}$, surely $A$ could decide that, since $\left\{\mathrm{H}_{3}\right.$, $\left.\mathrm{H}_{4}, \mathrm{H}_{5}\right\}$ is well confirmed, he must have been wrong in two of the three judgements he made at $\mathrm{t}_{8}$ : namely, both $\mathrm{s}_{1}$ and not-s. $\mathrm{s}_{2}$. And there are similar examples in which $A$ makes principled revisions to tokens of the remaining four types of judgement.

Another case: Wright argues there are no theories about two sensation types that generate criteria of correctness for all of the judgements a subject might make (p. 248). But, once we enlarge the range of theories on offer, this seems false. Consider,

$$
\mathrm{H}_{6}: \quad \mathrm{P}_{1} \Rightarrow \mathrm{P}_{2}
$$

Having recorded the following series of judgements

$\begin{array}{cccccccc}\mathrm{t}_{1} & \mathrm{t}_{2} & \mathrm{t}_{3} & \mathrm{t}_{4} & \mathrm{t}_{5} & \mathrm{t}_{6} & \mathrm{t}_{7} & \mathrm{t}_{8} \\ \mathrm{~s}_{1} & \mathrm{~s}_{2} & \mathrm{~s}_{1} & \mathrm{~s}_{2} & \mathrm{~s}_{1} & \mathrm{~s}_{1} & \mathrm{~s}_{1} & \mathrm{~s}_{2}\end{array}$

$A$ could reasonably conclude that both of his judgements at $\mathrm{t}_{6}$ were incorrect: $\mathrm{s}_{1}$ and not- $\mathrm{s}_{2}$. And having recorded the following series of judgements

$\begin{array}{llllllll}\mathrm{t}_{1} & \mathrm{t}_{2} & \mathrm{t}_{3} & \mathrm{t}_{4} & \mathrm{t}_{5} & \mathrm{t}_{6} & \mathrm{t}_{7} & \mathrm{t}_{8} \\ \mathrm{~s}_{1} & \mathrm{~s}_{2} & \mathrm{~s}_{1} & \mathrm{~s}_{2} & \mathrm{~s}_{2} & \mathrm{~s}_{2} & \mathrm{~s}_{1} & \mathrm{~s}_{2}\end{array}$

he could reasonably conclude that both of his judgements at $t_{5}$ were incorrect: $s_{2}$ and not- $s_{1}$. Wright has not explained why this theory and its more complex cousins fall short of generating criteria of correctness for all the judgements whose subject matter they concern. 
So Wright underestimates the potency of Blackburn's objection to Wittgenstein. If we concede that the aspirant private linguist might at least attempt to establish a criterion of correctness by theorising about his sensations, we cannot then defuse this concession's implications for the antiprivacy view by invoking Wright's meagre assessment of the linguist's odds of succeeding. For Wright's calculations are mistaken: he underestimates both the richness of the data and the range of theories that would be available to the linguist. Hence those of us who doubt the possibility of a private language must not allow the issue to come down to such a calculation of odds. ${ }^{8}$

David Bain

University of Nottingham

davidbain@fastmail.fm

\section{References}

Blackburn, S. (1984), “The Individual Strikes Back”, Synthese 58, pp. 281-301.

Carruthers, P. (1986), Introducing Persons (London: Croome Helm)

Harrison, R. (1974), On What There Must Be (Oxford: Clarendon Press).

Moore, A. (2003), “On the Right Track”, Mind 112, pp. 307-22

Walker, R. (1978), Kant (London: Routledge and Kegan Paul).

Wittgenstein, L (1953), Pbilosopbical Investigations, translated by G.E.M. Anscombe. (Oxford: Basil Blackwell).

Wright, C. (1986), "Does Philosophical Investigations I. 258 Suggest a Cogent Argument Against Private Language?", in McDowell, J. and P. Pettit (eds.), Subject, Thought, and Context (Oxford: Oxford University Press), pp. 209-266.

\footnotetext{
${ }^{8}$ For discussion and comments, I am extremely grateful to Simon Blackburn, Bill Child, James Ladyman, Doug Long, Jay Rosenberg, Andrew Woodfield, and Crispin Wright.
} 